\title{
Faculty Perceptions of Loughborough's Online Reading List System (LORLS) at Dublin Business School (DBS) Shortened Title $=$ Faculty Perceptions of LORLS at DBS
}

Lara Musto, (MA, MSc ILM), Council Member of the Careers Development Group, Library Association of Ireland and Qualified Language Teacher (English, Spanish and Italian) and Librarian.

Lara Musto

48 Bayside Crescent,

Sutton,

Dublin 13.

Tel: $+35386-8247268$

Email: lara.musto@gmail.com

Marie O’ Neill, (B.A, Grad DipLIS, GradDipBus, MA ILM), Head of Library Services, Dublin Business School.

Contact Details

Marie O’ Neill,

Head of Library,

13-14 Aungier Street,

Dublin 2.

Tel: $+3531-4177571$

Email: marie.oneill@dbs.ie

Fax: 35314177543

\section{Marie O' Neill is the Editorial Contact.}

Declaration: This manuscript has not been published elsewhere and it has not been submitted simultaneously for publication elsewhere. All figures and tables are owned by the authors of this study with the exception of figure 1 which has been taken directly from a journal article and has been properly referenced. 


\section{Abstract}

This article explores faculty perceptions of Loughborough's Online Reading List System (LORLS) at Dublin Business School (DBS), where it was installed in 2014. Data generated by the study will inform, advocacy, marketing and training initiatives to promote the platform. LORLS provides library users with access to online reading lists with live links to library catalogue records, e-books, e-journal articles, e-journals titles and websites.

A mixed methods research style, comprising qualitative and quantitative approaches was carried out for the purposes of this study. Data was gathered from full-time and part-time lecturers from the Business, Law and Arts faculties.

The study concludes with a number of deductive and inductive findings. The first is that although DBS faculty are highly predisposed to using LORLS, there are a number of variables that impact its use. Non-arts faculty who were teaching part-time and for a shorter period of time tended not to be as aware of LORLS. These variables must be considered in the context of advocacy, marketing and training initiatives in relation to LORLS implementation. Grounded theory analysis of the focus group data also revealed that faculty would like LORLS to have greater interoperability with the virtual learning environment (VLE) Moodle which is used at DBS.

A key output of the study is a LORLS Process Implementation Chart for proposed inclusion on the LORLS developers' implementation blog to assist other organisations with LORLS adoption. The chart synthesises the key findings of the literature review and of the data generated in this study. 


\section{Introduction}

At the time of this study, just two academic institutions in Ireland were using a reading list software: WIT Library (an in-house system designed by David Kane, Systems Librarian) and DBS Library (LORLS). Consequently it was felt by the researchers that a case study could provide illuminating insights to help increase uptake of the software in DBS; to inform the adoption of reading list software in the higher education sector in Ireland and to contribute to a small but growing body of literature on reading list software.

LORLS gives library users access to online reading lists with live links to library catalogue records, e-books, e-journal articles, e-journal titles and websites. Faculty can create, edit and annotate reading lists. Library catalogue records can be directly ingested into LORLS from the library catalogue. LORLS also provides useful analytics via a dashboard which illustrates the number of times reading lists have been viewed. Students can also rate reading list items with a thumbs up or thumbs down providing faculty with data in relation to which books students find helpful or challenging. In addition to this, LORLS has a library stock ordering function.

Considering the centrality of the reading list to the teaching and learning experience in higher education, few academic studies have been devoted to it. This article explores faculty attitudes to the implementation of LORLS at DBS.

\section{Literature Review}

\section{Introduction}

The literature on reading list software can be divided into four dominant themes

- Reading lists and pedagogy

- The design and development of reading list software 
- The evaluation and implementation of reading list software

- Faculty and student perceptions of reading lists and reading list software

The bulk of the literature on reading lists and on reading list management systems has been authored by systems librarians who have designed, implemented and developed these systems. Consequently a small number of authors have written extensively on the subject, some authoring several papers.

\section{Reading Lists and Pedagogy}

Derven (2011) states that the literature on reading list software also "bridges the provinces of the library and teaching and learning faculties" (p.3). The pedagogical value of reading lists are highlighted by Stokes and Martin (2008) who suggest that "one of the primary purposes of constructing a reading list was the pastoral aim of offering students a 'sense of direction' in relation to writing on a given field" (p.116). Rowley et al. (2008, p.) suggest that reading lists have a critical role to play in transforming students into autonomous learners.

Conversely, Stokes and Martin (2008, p.13) also address concerns that reading lists are a form of 'spoon-feeding' that inhibit independent learning. Masson (2009, p.223) suggests that reading list software offers the potential to circumvent the passivity of traditional print reading lists. He states that:

"The emergence of collaborative resource list tools that support the development process and user tagging will transform the utility of the resource list from a static reference tool to a scaffolding learning support activity." (p.223)

Siddal and Rose (2008, p.57) suggest that annotated and technologically enhanced reading lists can assist with information literacy practice i.e. evaluating information.

Atkinson et al. (2010, p.76) highlight the lack of engagement by faculty with the library in relation to submitting or updating their reading lists. Brewerton (2013, p.2) and 
Morgan (2007, p.263) identify faculty as the main drivers of reading list software adoption. Jones (2009) also states that:

"Academics are the drivers of reading list systems in that they actually create and maintain reading lists. Without widespread academic participation any standard system would fail.” (p.12)

\section{Creation and Design of Reading List Software}

A larger proportion of the articles written on the design and development of reading list software have been written by the Systems Librarian Team at Loughborough University. LORLS has been in existence since 2003. Less literature has emerged from librarians using proprietary solutions. Bartlett (2010) a senior analyst for Talis, writes on the implementation of Talis Aspire, proprietary reading list software at Nottingham Trent University. Cross (2015) also discusses the implementation and promotion of Talis Aspire at Nottingham Trent University whilst Morgan (2007) discusses the installation of Talis List at the University of Glamorgan. More studies from librarians using proprietary software would augment the body of literature on this subject.

Brewerton and Knight (2003, p.189) discuss the factors that contributed to the development of LORLS at Loughborough University in the first instance. Lecturers at Loughborough University could not create, edit or annotate reading lists outside of the library management system (LMS). There was also no scope within the LMS to include journal articles. LORLS enables lecturers to create and edit their own reading lists. The software links to the library catalogue but can also incorporate links from databases and the internet.

Recent papers by the LORLS development team focus on new developments and upgrades to the system. An article published in 2013 by Cooper et al. focuses on the development of a dashboard interface which provides valuable analytics for academics on the 
number of times reading lists are viewed and the number of times items on reading lists are borrowed (Fig.1). Users of LORLS also have the opportunity to rate items on reading lists that they like or dislike with a simple thumbs up or thumbs down. Cooper et al. (2013) state that:

Feedback has been very positive with many academics praising the graphical design of the dashboard and appreciating the insight the dashboard gives them into the use of their reading lists. (...) Areas that are currently under investigation to be added or enhanced in future versions of the dashboard include loan information, pricing and download counts for online items. (no page, open access journal)

Brewerton (2014, p.78) suggests that information generated by LORLS is critical in relation to the library's purchasing decisions. For this reason LORLS recently incorporated a purchasing predictor application which automates stock ordering based on predefined student to text ratios and allocated budgets.

Other authors on reading list software have focused on the requirement for reading list systems to have interoperability with other library systems. Chad (2010 p.3) commends proprietary LMS companies such as Talis and Ex Libris which have developed reading list systems that link up with VLEs and other college software/systems. Derven (2011) concurs with this viewpoint stating that "Ideally, a reading list system ought to be a flexible service that uses data from a Library's LMS while also discoverable through a VLE.” (p.2)

\section{Evaluation and Implementation of Reading List Software}

Hew Jones (2009) a Systems Support Librarian suggests in his examination of reading lists at Cambridge University that "Reading lists are the area in which academic workflows, student needs and library services interact most directly" (p.3). He advocates for standardisation in 
relation to reading list processes at Cambridge University. He states that the main problem with reading lists in the institution is “(...) the lack of a standard way of handling them” (p.5). Cross (2015) agrees with Jones. Not having a standard criterion for handling reading lists institutionally was the impetus for the installation of Talis Aspire at Nottingham Trent University. He states that:

In addition to the question of inconsistent coverage, the reading list environment was also seen as confused and difficult to navigate. Some lists were included in module guides, other lists were loaded into the VLE filestore, while others were handed out in print format during lectures or seminar sessions on a just-in-time basis throughout the course. (p.212)

Derven (2011, p.13) advocates that prior to the implementation of reading list software, consideration should be given to shared systems and services between academic institutions to reduce costs. Like Jones (2009) and Cross (2015), he highlights the importance of the standardisation of reading list workflows going a step further by advocating that a mutual standardised data template and workflow for reading lists across academic institutions in Ireland should be drawn up.

Cross $(2015$, p.220) suggests that staff resistance to reading list software is an issue particularly in the context of time constraints. Bartlett (2010) underlines the benefits Talis Aspire affords in improving communications between library staff, academics and students at Nottingham Trent University where the software also links to the VLE, to the student registry and to SAML authentication systems so that students have a personalised experience when viewing online reading lists. Bartlett (2010) envisages a time where reading lists will be shared across institutions “(...) especially at a time in the higher education sector when collaboration has never been so important" (p.43). 
In the supplier news of the February 2013 CILIP Update, a feature describes Talis Aspire Digitised Content "which is one of the first services to utilise the Copyright Licencing Agency's (CLA) new API that gives UK universities real-time copyright permissions” (p.20). Reading list software provides a huge opportunity within the higher education environment to facilitate greater copyright compliance.

Derven (2011, p.23) proposes a framework for the implementation of reading list software, which includes integration and interoperability with other college systems such as the VLE, the LMS, financial and registry services; the establishment of institutional reading list templates; data ingest and data import and export features; automated processes over manual; the ability for academics to annotate reading lists and to add items from vendors and other online resources as well as student focused interfaces that enhance research skills. Derven concludes his paper with a note of caution about open source reading list software stating that institutions may not have the financial means and technical expertise to adapt and support the software in their institution. He does assert however that "LORLS is the strongest open source option" (p.22).

Brewerton (2013) suggests that the process of reading list software installation "(...) would greatly benefit from the support and involvement of senior management" (p.2). He also reinforces that "academics as the creators of the reading list are obviously key to the success of the project" (p.2).

\section{Faculty and Student Perceptions/Use of Reading Lists and Reading List Software}

Stokes and Martin (2008) in their study of tutor and student attitudes towards reading lists at the University of Central Lancashire found that:

A clear expectation expressed by tutors was a desire for students at all levels to read widely, not only from the reading lists but also beyond these sources. This 
was seen as an integral element of developing student ability and autonomy.

(p.117)

Their research indicates that $18 \%$ of first year students did not consult reading lists at all and $67 \%$ consulted no more than four items; "However, as might be anticipated, there was more evidence of exploration and proactive reading beyond the reading list in the level three students" (p.120).

Brewerton (2014) analyses qualitative data generated by previous questionnaires administered to faculty and students of Loughborough University in 2011. Brewerton's study of comments in the questionnaires produces similar findings to Stokes and Martin's research (2008). Many lecturers at Loughborough University feel that their reading lists are not being consulted even though relevant chapters have been pointed out or conversely that students don't read beyond the reading list; students complain that some reading lists are too long and that their contents are out of date (Brewerton, 2014, pp. 84-86).

Stokes and Martin (2008) advocate the use of annotated bibliographies and reading list software to foster greater engagement with students in the context of reading lists calling for “(...) a re-examination of this stalwart of the academic environment” (p.124).

\section{Methodology}

This study was carried out in the summer of 2015. A mixed methods approach was employed which combined a questionnaire and focus groups. The questionnaire comprised closed and open ended questions and was constructed around four hypotheses:

1. Does the part-time or full-time status of lecturers' impact awareness and use of

\section{LORLS?}


2. Does the number of years that a lecturer has been teaching impact awareness of and use of LORLS?

3. Does the number of hours a lecturer teaches impact awareness and use of LORLS?

4. Does the discipline in which a lecturer teaches impact awareness and use of LORLS?

The questionnaire was distributed to all DBS faculty (two hundred and fifty in total) via Survey Monkey. A total of forty respondents replied to the survey (16\% of the survey sample). The aim of the focus groups by contrast was to obtain more extensive qualitative data from faculty in relation to the use and perception of LORLS. Data generated by the focus groups was subsequently coded to identify common themes and to expand upon and advance the theory pertaining to LORLS and reading list software. Sixteen faculty staff members attended the focus groups.

The ultimate goal of the study was to produce a LORLS Implementation Process chart for inclusion on the LORLS blog to support the extrapolation of findings and to inform the adoption of LORLS software in other institutions. Figure 2 illustrates the research paradigms and strategies employed in this research.

\section{Results and Data Analysis}

\section{Survey Findings}

\section{Hypotheses}

The four hypotheses of the study were confirmed. The following variables do impact the uptake and use of LORLS. 


\section{Lecturing status (full-time versus part-time)}

$76 \%$ of full-time staff were aware of LORLS versus $47 \%$ of part-time staff. Advocacy, marketing and training initiatives pertaining to LORLS must focus more strongly on the part-time faculty.

\section{Number of lecturing hours Per Week}

$64 \%$ of full time lecturers who taught 10-19 hours per week were aware of LORLS compared to $4 \%$ of full-time lecturers teaching less than ten hours per week. The effect of teaching less hours was confirmed in relation to full-time faculty (Fig.3). This was not confirmed in relation to part-time faculty.

\section{The subject discipline in which a lecturer teaches}

$79 \%$ of arts faculty were aware of LORLS compared to $44 \%$ of business (Fig. 4) Marketing and advocacy activities in relation to LORLS use must be tailored to each discipline.

\section{Number of years lecturing}

$75 \%$ of faculty lecturing for eleven years or more were aware of LORLS compared to $44 \%$ of those lecturing five years or less (Fig.5).

The profile of a faculty staff member who is less likely to be aware of or use LORLS is younger; teaches on a part-time basis; has been teaching for a shorter amount of time and is more likely to be from the business faculty. Full-time faculty who are teaching fewer hours (less than ten hours per week) are also less likely to be aware of LORLS. The survey illustrated that younger part-time faculty, as opposed to long serving staff members, are more motivated to find out about LORLS however if they were not already informed about it. Other key statistics revealed in the survey include:

- $53 \%$ of respondents were unaware of institutional reading list templates even though they are available at DBS. This confirms the findings of Brewerton (2014, p.87), 
Cross (2015, p.221) and Jones (2009, p.7) which indicates a lack of standardisation and/or awareness of the processes pertaining to reading list management institutionally.

- $72 \%$ of faculty send reading lists to the library annually so that texts on reading lists can be acquired and updated. One quarter of faculty do not submit reading lists. A study by Atkinson et al. (2010, p.75) had similar findings.

- $93 \%$ of faculty would like students to read beyond the reading list; similar findings are indicated in studies by Stokes and Martin (2008, p.117) and Brewerton (2014, p.82).

- $65 \%$ of respondents had heard of LORLS. Of those who hadn't heard of LORLS, $80 \%$ suggested that they would be interested in finding out more about it. There is an appetite amongst faculty at DBS to use reading list software.

- Just $21 \%$ of respondents attended LORLS training offered by the Library. Open ended feedback to questions about LORLS training indicated a preference amongst faculty for LORLS training outside of busy teaching periods, for example during the summer. Additionally, faculty suggested that multi-media tutorials on LORLS should be available.

- The main barriers to using LORLS was lack of time (81\%), followed by lack of awareness $(27 \%)$. Cross $(2015$, p.220) also refers to staff time constraints as a key barrier to the uptake of reading list software. $3 \%$ of faculty mentioned that they were not comfortable with any kind of classroom technology. Digital literacy training for faculty could support the promotion and uptake of LORLS. 


\section{Advantages and Disadvantages of LORLS}

In an open ended question, faculty were asked to describe what they would change about LORLS. This elicited the following comments:

"Nothing"

"I would like one login to all resources"

"My knowledge of the resource!"

"Embed into Moodle so that when I log into Moodle, I can update my LORLS list without logging in separately. Tick an option on Moodle so that if I upload a pdf of an article on my Moodle page, it can be automatically added to the LORLS list."

"Be more integrated with Moodle.

A query about listing one or more of LORLS' primary advantages garnered the following results (Fig.6):

- It promotes library resources (64\% of respondents).

- Highlights key resources on reading lists (52\% of respondents).

- Improves communication with the library (36\% of respondents).

- Stores one's reading list in a central online location (32\% of respondents).

- Provides LORLS usage statistics (20\%).

- It is useful for programmatic review or quality assurance events (12\%).

- It showcases teaching excellence (4\%). 


\section{Focus Group Findings}

Focus group feedback was analysed using a grounded analysis approach. Focus group participants were also highly positive about LORLS. Positive comments included:

"I like that you can link easily to videos, articles on a LORLS reading lists."

"I like the way items on the LORLS lists links to the catalogue."

Focus group data also revealed similar themes to the survey findings in relation to faculty perceptions of reading lists and LORLS including time constraints and the desire for students to read beyond the reading list. A stronger emphasis was placed by focus group participants on the lack of interoperability of LORLS with the VLE. Authors such as Chad (2010) and Derven (2011) emphasise the importance of reading list software and interoperability with other platforms such as the VLE. Quotes from focus group participants include:

"There is currently a need to populate LORLS then insert a LORLS link into Moodle which feels like double population."

Focus group participants also expressed a desire for LORLS to incorporate a reference management feature.

"Where does Zotero fit into this? I don't like that LORLS contains electronic references and Zotero also looks at the referencing of these electronic resources. It sounds like two robots sitting in the same room not talking to each other. Could 
a reference management tool be built into LORLS? I don't want to press the same button twice. We need to reduce replication. Why do two things when you can do one thing?"

\section{The Role of the Reading List in Higher Education Today}

Survey and focus group data in the current research provided interesting insights into the role of the reading list in higher education today which are of value to the library profession. For example one question in the survey asked respondents to identify what informed their choice of materials on a reading list (Fig 7). Faculty could select more than one option. The highest score was colleagues' recommendations ( $70 \%$ of respondents), whilst library staff recommendations were the lowest at $16 \%$. The online library catalogue only accounted for $33 \%$ of responses. Masson $(2009$, p. 219$)$ discusses the potential for reading list software to reinvigorate communication between faculty and the library in relation to reading lists.

One focus group question asked faculty if the reading list is obsolete in higher education today. This answer also revealed interesting insights including:

"No. They are a good starting point for the student."

"No. Reading lists help to keep faculty at the forefront of their field as they force faculty to keep up to date."

"One of the challenges nowadays is recognising that students are reading more than books and articles. They are reading the review section of IMDb for example. Reading lists have to change and our perception of reading lists." 
"No. Lecturer acts as a glorified filter. The lecturer takes in a lot of information sources - journal articles and decides what useful or good quality is. Reading lists mediate the information explosion."

"By asking students to read beyond the prescribed reading lists we are asking them in a way to create their own reading lists. Reading lists are an essential part of third level"

\section{Limitations to the Study}

Due to the work pressures of the authors and of faculty, the opportunity to conduct the current research did not arise until the academic year was completed. Factor that impacted negatively to the level of responses received to the survey (40 respondents out of 250 academics). In addition to this, the small number of respondents to the survey from the Law Faculty (1 respondent) means that the bulk of quantitative data obtained in the study pertains to arts and business faculty solely. Element that was counterbalanced by data obtained from additional faculty during the focus groups.

A case study is localised. To aid with the extrapolation of findings the research data was compared with the academic literature for complementarity and variance. A LORLS Implementation Process chart for inclusion on the LORLS blog was also created synthesising the key findings of this research and of the literature review (Fig.8). The process implementation chart could be used by other institutions wishing to adopt LORLS.

\section{Recommendations}

To aid with the implementation of LORLS at DBS and elsewhere the authors recommend that institutions:

- Secure the backing of senior management. 
- Review reading lists workflows and procedures at institutional level to produce greater standardisation.

- Ensure that faculty are aware of institutional reading list templates and workflows.

- Seamless access to LORLS is provided by using access management software such as Shibboleth.

- LORLS training is provided at specific points in the semester when faculty have less time pressures. Multi-media tutorials must also be created to support LORLS training.

- Training and advocacy initiatives must be mindful of variables such as faculty length of service, whether faculty are full or part-time, the discipline in which faculty teach etc.

- LORLS training should be carried out as part of broader digital literacy training for faculty.

- LORLS developers consider building a connector between LORLS and a range of VLEs so that any new reading list created on LORLS is automatically ingested into the relevant module page on the VLE.

- It is proposed that the LORLS Implementation Process Chart (Fig.8) be added to the LORLS developers' implementation blog (https://blog.lboro.ac.uk/lorls/) as both a blog entry and as part of LORLS documentation. The chart can be revised and adapted as new research comes to light.

\section{Further Study}

Further areas of research that would provide highly useful data and insights include:

- Librarians' perceptions of and use of LORLS

- Student' perceptions of and use of LORLS

- Usability studies (faculty, student and librarian) 


\section{Conclusion}

Using deductive and inductive approaches to research, this study has revealed two principles findings that had not been uncovered in the literature on reading lists to date.

1) The first finding emerged from the survey. The survey revealed that four variables in relation to DBS faculty impact the awareness and use of LORLS. These are:

- Lecturing status (full-time versus part-time)

- Number of lecturing hours

- The subject discipline in which a lecturer teaches

- Number of years lecturing

The profile of a faculty staff member who is less likely to be aware of or use LORLS is younger; teaches less hours; has been teaching for a shorter amount of time and is more likely to be from the business faculty. Full-time faculty who teach fewer hours (less than ten hours per week) are also less likely to be aware of LORLS. Younger part-time faculty who have not been teaching as many years are highly motivated however to find out more about LORLS. Conversely, longer length of service can militate against faculty having an interest in finding out more about new products and services.

2) Faculty also have a strong desire for LORLS to have greater interoperability with Moodle.

The LORLS development team at Loughborough University are highly committed to LORLS and support from the team has been superb from the outset. Feedback from this research has been relayed to them and will inform future updates.

LORLS has transformed the reading list experience at DBS not just for students and faculty but also for Library staff. For the first time, all of the College's 600 reading lists are stored in one central location, LORLS. The functionality of the platform has also streamlined 
workflows around the acquisition, updating and dissemination of reading list content and enhanced communication between the Library, faculty and students.

For further information on LORLS, please go to https://blog.lboro.ac.uk/lorls/

\section{Reference List}

Atkinson, S. Conway, N. Taylorson, B. \& Smith, C. (2010). Reading lists - pitching it right. SCONUL Focus, 50, pp. 75-79. (Accessed: $14^{\text {th }}$ October 2015)

Bartlett, S. (2010). Resource list management: a system-based approach. Library and Information Update. June 2010, pp. 42-43.

Brewerton, G. (2014). Implications of student and lecturer qualitative views on reading lists: a case study at Loughbourgh University, UK. New Review of Academic Librarianship, 20 (1), pp. 78-90. Library and Information Science Source, EBSCOhost [Online]. (Accessed: $14^{\text {th }}$ October 2015)

Brewerton, G. (2013). Implementing a resource or reading list management system. Ariadne, 71. Available at: http://www.ariadne.ac.uk/issue71/brewerton (Accessed: $14^{\text {th }}$ October 2015)

Brewerton, G. \& Knight, J. (2003). From local project to open source: a brief history of the Loughborough Online Reading List System (LORLS). VINE: The Journal of Information and Knowledge Management Systems, 33 (4), pp.189-195. Library and Information Science Source, EBSCOhost [Online]. (Accessed: $14^{\text {th }}$ October 2015) 
Chad, K. (2010). A perspective on resource list management. Library \& Information Update, CILIP June 2010, pp. 39-41. (Accessed: $14^{\text {th }}$ October 2015)

Cooper, J. Knight, J. \& Brewerton, G. (2013). Providing information about reading lists via a dashboard interface. Code4Lib, 19. Available at: http://journal.code4lib.org/articles/7745 (Accessed: 05th November 2015)

Cross, R. (2015). Implementing a resource list management system in an academic library. The Electronic Library, 33 (2) pp. 210-223. Available at: http://dx.doi.org/10.1108/EL-052013-0088 (Accessed: 05th November 2015)

Derven, C. (2011). Evaluating services and specifications for reading list systems (Working Report). ANTLC/Swets, Available at: http://anltc.conul.ie/wpcontent/uploads/2013/01/ANLTCReport-CalebDervenReadingLists1.pdf (Accessed: $14^{\text {th }}$ October 2015)

Jones, H. (2009). Reading Lists in Cambridge: A Standard System? (Working Report). DSpace@Cambridge [Online]. Available at:

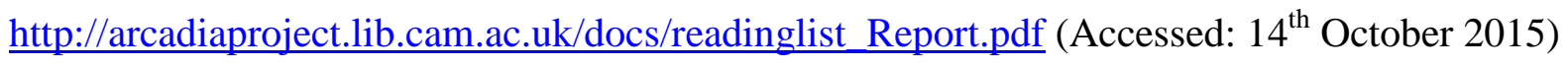
Masson, A (2009). VRE library services: learning from supporting VLE users. Library Hi Tech, 2, p. 217. Academic OneFile, EBSCOhost [Online]. (Accessed: 05th November 2015) 
Morgan, R. (2007). The online reading list project using Talis List at the University of Glamorgan. Program, 41 (3), pp.262-275. Emerald Database [Online]. (Accessed: 05th November 2015)

Rowley, M. Hartley, J. \& Larkin, D. (2008). Learning from experience: the expectations and experiences of first-year undergraduate psychology students. Journal of Further and Higher Education, 32 (4), pp.399-413. (Accessed: 05th November 2015)

Siddal, G. \& Rose, H. (2014) Reading lists - time for a reality check? An investigation into the use of reading lists as a pedagogical tool to support the development of information skills amongst Foundation Degree students. Library and Information Research, 38 (118), pp. 5273. (Accessed: 05th November 2015)

Stokes, P. and Martin, L. (2008). Reading lists: a study of tutor and student perceptions, expectations and realities. Studies in Higher Education, 33(2), pp. 113-125. Library and Information Science Source, EBSCOhost [Online]. (Accessed: 05th November 2015)

Talis Aspire (2013). Talis Aspire adds new copyright service. CILIP Update (February), Supplier News. (Accessed: $14^{\text {th }}$ October 2015) 